\title{
Effects of Trinexapac-ethyl on Drought Responses in Creeping Bentgrass Associated with Water Use and Osmotic Adjustment
}

\author{
Xiuju Bian \\ Department of Crop Science, Agricultural University of Hebei, Baoding, China 071001 \\ Emily Merewitz and Bingru Huang ${ }^{1}$ \\ Department of Plant Biology and Pathology, Rutgers University, New Brunswick, NJ 08901
}

\begin{abstract}
AdDitional INDEX wORDs. Agrostis stolonifera, growth regulator, solutes, stress tolerance
AbSTRACT. Understanding factors influencing drought resistance traits is important for improving turfgrass growth in water-limited environments. The objectives of this study were to examine effects of a plant growth regulator, trinexapac-ethyl (TE), on turf growth and water use for creeping bentgrass (Agrostis stolonifera L.) exposed to drought stress, and to determine changes in the accumulation of solutes involved in osmotic adjustment associated with TE application. Plant foliage of cultivar $L-93$ was sprayed with $1.95 \mathrm{~mL} \cdot \mathrm{L}^{-1}$ of $\mathrm{TE}$ at $0.113 \%$ a.i. 14 days before and at the initiation of drought stress. TE-treated and untreated plants were exposed to well-watered or drought stress conditions for 28 days in a growth chamber. TE-treated plants exhibited a reduced rate of water depletion from the soil as demonstrated by higher soil water content, lower evapotranspiration rates, and higher leaf relative water content during 28 days of drought stress compared with non-TE-treated plants. During the later phase of drought stress, TE-treated plants had a greater reduction in leaf $\psi_{\mathrm{S}}$ at full turgor or greater osmotic adjustment, which was associated with increased accumulation of soluble sugars and inorganic ions (Ca and K) in leaves of TE-treated plants. Proline content increased in response to drought stress, but was unaffected by TE application, suggesting that it may not contribute to the effects of TE on osmotic adjustment. TE-treated plants maintained significantly higher turf quality and leaf photochemical efficiency under drought stress. The results suggest that the promotive effects of TE application on turf growth during drought stress were associated with the reduction in water depletion or lower water use and increases in osmotic adjustment due to the accumulation of inorganic solutes and soluble sugars.
\end{abstract}

The water resources available for the irrigation of turfgrass have become increasingly restricted in recent years due to periods of insufficient precipitation, increased domestic, agricultural, and industrial consumption, and contamination of potable water supplies. In many areas, the water deficit has resulted in implementation of water conservation strategies and stringent restrictions in water use. Therefore, developing watersaving cultural practices for turfgrass management is important in areas with a limited water supply. In addition, further insights into the mechanisms that impart low water consumption in turfgrasses can serve as selection criteria for water-saving turfgrass species or cultivars.

The maintenance of cellular hydration is critical for plant survival in water-limiting environments, which may be achieved by one or the combination of drought avoidance traits such as increasing water uptake from the soil and reducing transpirational water loss by stomatal closure, and drought tolerance traits such as water retention for cell turgor maintenance through osmotic regulation (Nilsen and Orcutt, 1996). Various cultural practices have been used for water conservation in turfgrass management, including the use of plant growth regulators (PGRs). Trinexapac-ethyl (TE) is one of the most

Received for publication 7 July 2009. Accepted for publication 17 Aug. 2009 We wish to thank Yan $\mathrm{Xu}$ and Chenping $\mathrm{Xu}$ at Rutgers University for critical reviewing the manuscript, and we express sincere thanks to the Chinese Scholarship Council and Rutgers Center of Turfgrass Science for partial funding support of this collaborative research project between Agricultural University of Hebei, Hebei Province, China and Rutgers University.

${ }^{1}$ Corresponding author. E-mail: huang@aesop.rutgers.edu. widely used PGRs in the management of cool-season and warmseason turfgrass species (Fagerness et al., 2002; Heckman et al., 2001; Lickfeldt et al., 2001; McCullough et al., 2006). TE is absorbed quickly by foliage and slows cell elongation by inhibiting the conversion of one form of gibberellic acid (GA20) to another (GA1). TE has been used mainly for clipping reduction, seedhead suppression in annual bluegrass (Poa аппиа $\mathrm{L}$.), and improvement of overall turf quality in various turfgrass species (Fagerness et al., 2002; Lickfeldt et al., 2001; McCullough et al., 2006). Several recent studies reported that TE also improved turfgrass tolerance to environmental stresses, such as salinity in bermudagrass [Cynodon dactylon (L.) Pers.] (Baldwin et al., 2006), heat stress in kentucky bluegrass (Poa pratensis L.) (Heckman et al., 2001), drought in zoysiagrass (Zoysia japonica Steud.) and perennial ryegrass (Lolium perenne L.) (Jiang and Fry, 1998), and simultaneous drought and heat stresses in creeping bentgrass (McCann and Huang, 2007). Ervin and Koski (2001) reported that TE resulted in lower evapotranspiration (ET) rates and reduced clipping yield in kentucky bluegrass. Previous studies on the influence of TE on turfgrass stress responses mainly focused on growth effects and the reduction in water demand associated with growth inhibition. However, TE may regulate other physiological processes involved in stress tolerance. In an earlier review article, Munns (1988) pointed out that growth reduction under drought stress may also contribute to osmotic adjustment, with a $30 \%$ reduction in a relative growth rate of leaves resulting in a reduction in $\psi_{\mathrm{S}}$ by 0.1 to $0.2 \mathrm{MPa}$, assuming that assimilation rate of solutes are unaffected. Based on this notion, it is anticipated that TE may also influence drought resistance 
ability through changing $\psi_{\mathrm{S}}$ when shoot growth rate is inhibited.

Osmotic adjustment associated with the accumulation of solutes is a major factor regulating dehydration tolerance in higher plants, which is associated with increased movement of water into or reduced water efflux from cells (Blum, 1988). Therefore, osmotic adjustment helps to maintain cell turgor at a given leaf water potential and thus delays wilting of leaves and enables tissues to sustain growth and metabolic and physiological functions at lower plant water status (Munns, 1988). The types of osmotically active solutes associated with osmotic adjustment are diverse and typically include low molecular weight compounds such as amino acids (e.g., proline), ammonium compounds (e.g., glycine betaine), sugars (e.g., fructans, sucrose), polyols (e.g., mannitol), inorganic ions (e.g., potassium, calcium), organic acids (e.g., malate), and hydrophilic proteins [e.g., late embryogenesis abundant (LEA)] (Chaves et al., 2003). How TE may affect the drought tolerance trait of water retention related to osmotic regulation is not well understood. Understanding how improved drought tolerance with TE is related to its effects on different water use characteristics (water loss and/or retention) would provide further insight into drought resistance mechanisms that may be manipulated through plant growth regulation.

The objectives of this study were to examine the effects of TE application on turf growth and water use characteristics for creeping bentgrass subjected to drought stress and to determine changes in the accumulation of solutes involved in osmotic adjustment associated with TE application.

\section{Materials and Methods}

\section{Plant materials and treatments}

Creeping bentgrass (cv. L-93) sod (10 cm in diameter and $1.0 \mathrm{~cm}$ thick) with roots being trimmed off was collected from the turfgrass research farm at Rutgers University, New Brunswick, $\mathrm{NJ}$, and transplanted into plastic pots $(10 \mathrm{~cm}$ in diameter and $40 \mathrm{~cm}$ deep) filled with the same amount of soil (fine-loamy, mixed mesic Typic Hapludult). Plants were maintained in a greenhouse for $45 \mathrm{~d}$ with 10 to $12 \mathrm{~h}$ natural light conditions and temperatures of $\approx 21 / 13{ }^{\circ} \mathrm{C}$ (day/night). Following a 45-d plant establishment in the greenhouse, plants were transferred to a walk-in growth chamber $(2.5 \times 3 \mathrm{~m})$ where treatments were imposed. The growth chamber was maintained at $20 / 15{ }^{\circ} \mathrm{C}$ (day/night), 68\% relative humidity, photosynthetically active radiation $(P A R)$ of $550 \mu \mathrm{mol} \cdot \mathrm{m}^{-2} \cdot \mathrm{s}^{-1}$ at canopy height, and a $12-\mathrm{h}$ photoperiod. Plants in each pot were fertilized biweekly with $100 \mathrm{~mL}$ of a soluble fertilizer (20N-8.8P-16.6K) (Peter's General Purpose 20-20-20; Grace-Sierra Horticultural Products, Milpitas, CA), including micronutrients at a concentration of $5 \mathrm{~g} \cdot \mathrm{L}^{-1}$ in $100 \mathrm{~mL}$ of the soluble fertilizer $(0.05 \% \mathrm{Mg}$, $0.0068 \%$ B, $0.0036 \% \mathrm{Cu}, 0.05 \% \mathrm{Fe}, 0.025 \% \mathrm{Mn}, 0.0009 \% \mathrm{Mo}$, and $0.0025 \% \mathrm{Zn}$ ) before exposure to drought. Plants were watered three times a week until drainage occurred from the bottom of each pot. The turf canopy of each pot was handclipped weekly to a height of $\approx 1.0 \mathrm{~cm}$ and clippings were removed from the pot.

\section{Treatments and experimental design}

The experiment consisted of four treatments: 1) wellwatered plants without TE application (control), 2) wellwatered plants with foliar application of TE (control $+\mathrm{TE})$,
3) drought stress without foliar application of TE (drought), and 4) drought stress with foliar application of TE (drought $+\mathrm{TE}$ ). For TE treatment, turf foliage was sprayed $14 \mathrm{~d}$ before drought treatment began and on the day of drought stress imposition with a hand-held sprayer (Hudson Farm Tough; Hudson Manufacturing, Chicago) at a rate of $0.8 \mathrm{~L} \cdot \mathrm{ha}^{-1}\left[1.95 \mathrm{~mL} \cdot \mathrm{L}^{-1}\right.$ (v:v)] of $0.113 \%$ TE formulation (Primo Maxx; Syngenta Professional Products, Greensboro, NC) with a water carrying volume of $81 \mathrm{~L} \cdot \mathrm{ha}^{-1}$, which is the rate recommended by the manufacturer for growth inhibition of Agrostis L. spp. TE was not applied to the plants during the drought stress period. At each time when TE was applied in treatment 2 and 4, water in the same volume as TE application was also sprayed in treatment 1 and 3 . The spraying volume was controlled by recording the time in seconds it took to spray an area of $100 \mathrm{~cm}^{-2}$ (including eight pots, each $10 \mathrm{~cm}$ diameter) and calibrated using the solution volume sprayed into a bucket for the same time (number of seconds) as it took to spray the area. Well-watered plants were watered three times a week until water drainage occurred from the bottom of each pot, which replaced total water loss measured as ET rate. Drought stress was imposed by withholding irrigation for $28 \mathrm{~d}$. Each treatment was repeated in four replicates (four pots).

\section{Measurements}

WATER uSE Characteristics. Water use was evaluated by measuring soil volumetric water content (SWC) and ET rate. Volumetric soil water content was measured with the timedomain reflectometry (TDR) method by three-pronged buriable waveguide TDR probe (20 cm long) in the upper $20 \mathrm{~cm}$ of soil (Topp et al., 1980) using a Trase TDR instrument (Soil Moisture Equipment, Santa Barbara, CA). ET was determined by the gravimetric mass balance method. This was accomplished by weighing pots after drainage ceased with an electronic balance to calculate the total amount of water lost by comparing differences in pot weight between two measurement times at 24-h intervals (Young et al., 1997).

Leaf hydration or water status was determined by measuring leaf relative water content (RWC) and $\psi_{\mathrm{S}}$. RWC was determined according to the method of Barrs and Weatherley (1962) and was based on the following calculation: RWC = $(\mathrm{FW}-\mathrm{DW}) /(\mathrm{SW}-\mathrm{DW}) \times 100$, where $\mathrm{FW}$ is leaf fresh weight, $\mathrm{DW}$ is dry weight of leaves after drying at $85^{\circ} \mathrm{C}$ for $3 \mathrm{~d}$, and SW is the turgid weight of leaves after soaking in water for $5 \mathrm{~h}$ at room temperature $\left(\approx 20{ }^{\circ} \mathrm{C}\right)$. Osmotic potential $\left(\psi_{\pi 100}\right)$ was determined according to the rehydration method, where $\psi_{\pi 100}$ of leaves was determined after soaking in water for full rehydration (Rachmilevitch et al., 2006). Turgid leaf samples were frozen in liquid nitrogen and subsequently stored at $-20^{\circ} \mathrm{C}$ until analysis of leaf $\psi_{\mathrm{S}}$. Frozen tissue samples were thawed and cell sap was pressed from leaves using a hydraulic press (Campbell Scientific, Logan, UT), which was subsequently analyzed for osmolality [C (millimoles per kilogram)] using a vapor pressure osmometer (Vapro(C) model 5520; Wescor, Logan, UT). Osmolality of cell sap was converted from millimoles per kilogram to $\psi_{\mathrm{S}}$ (megapascals) using the formula: megapascals $=-\mathrm{C} \times 2.58 \times 10^{-3}$.

GROWTH AND OSMOTIC SOLUTE ANALYSIS. Overall turf quality and photochemical efficiency were determined as drought stress indicators. Turf quality was rated visually as an integral of grass color, uniformity, and density on a 0 to 9 scale, where $0=$ brown, dead turf; and $9=$ dark green and dense turf (Beard, 
1973). The minimum acceptable quality level was 6. Leaf photochemical efficiency was estimated by measuring the variable to maximum fluorescence ratio $(\mathrm{Fv} / \mathrm{Fm})$ in the nonenergized state accomplished by exposure of leaves to darkness for $30 \mathrm{~min}$. Measurements were made of intact leaves using leaf clips provided with the chlorophyll fluorescence meter (ADC BioScientific, Hoddesdon, UK). Clipping yield, which provides a measurement of shoot biomass production or overall turfgrass growth, was determined at the end of the 14-d TE treatment. Shoots were hand-clipped weekly to a height of $\approx 1.0 \mathrm{~cm}$. Clipping yield from each pots was measured after drying shoot clipping in an oven at $85{ }^{\circ} \mathrm{C}$ for $72 \mathrm{~h}$.

The content of two organic solutes (water-soluble sugars and proline) and two major inorganic osmotic solutes ( $\mathrm{K}$ and $\mathrm{Ca}$ ) were determined. Proline content was measured according to the procedure described by Bates et al. (1973) with modifications. About $0.2 \mathrm{~g}$ of fresh leaves were excised and wrapped in aluminum foil and were then immediately submerged into liquid nitrogen. Frozen leaf sample was ground with a mortar and pestle in $4 \mathrm{~mL}$ of $3 \%$ sulfosalicylic acid until homogeneity. The extraction was centrifuged at $16,000 g_{n}$ for $10 \mathrm{~min}$. A $100-$ $\mu \mathrm{L}$ aliquot was taken into a test tube with a final solution volume adjusted to $1 \mathrm{~mL}$ using double-deionized water. The reaction was initiated by adding $1.0 \mathrm{~mL}$ of acid ninhydrin $(1.25$ $\mathrm{g}$ of ninhydrin in $13.8 \mathrm{~mL}$ of $85 \% \mathrm{H}_{3} \mathrm{PO}_{4}, 30 \mathrm{~mL}$ of glacial acetic acid, and $6.2 \mathrm{~mL}$ of double-deionized water) and $1.0 \mathrm{~mL}$ of glacial acetic acid into each test tube, which were incubated in a water bath for $1 \mathrm{~h}$ at $100{ }^{\circ} \mathrm{C}$. The reaction was stopped by placing the test tubes in an ice bath. The absorbance of the reaction solution was read at $520 \mathrm{~nm}$ using a spectrophotometer. Proline content was determined using l-proline as a standard and was calculated based on dry weight of tissue. For analysis of water-soluble sugar content (WSC), $30 \mathrm{mg}$ of dry leaves was extracted four times for $15 \mathrm{~min}$ in $10 \mathrm{~mL}$ of boiling water. After centrifugation at $3500 \mathrm{~g}_{\mathrm{n}}$ for $10 \mathrm{~min}$, supernatants were collected and pooled, and the final volume was adjusted to $50 \mathrm{~mL}$. The WSC content was determined using the method described in Buysse and Merckx (1993). Briefly, $1 \mathrm{~mL}$ of supernatant was put into glass tube, and $1 \mathrm{~mL}$ of $18 \%$ phenol solution and $5 \mathrm{~mL}$ of concentrated sulfuric acid were added. The mixture was shaken, and absorbance was read at $490 \mathrm{~nm}$ using a spectrophotometer (GENESYS 2; Spectronic Instruments, Rochester, NY).

For the analysis of inorganic solute concentration, leaves were frozen in liquid nitrogen immediately after being detached from the plant. Cell sap was collected into minicentrifuge tubes with a hydraulic press and was stored at $-20{ }^{\circ} \mathrm{C}$ for analysis. The concentration of $\mathrm{K}^{+}$and $\mathrm{Ca}^{2+}$ in the cell sap was determined on a 1:100 (v/v) dilution using an inductively coupled plasma spectrophotometer (ICP) (Fisons Instruments, Beverly, MA) (Jiang and Huang, 2001).

\section{Experimental design and statistical analysis}

The experiment consisted of two factors (TE treatment and water treatment) arranged as a completely randomized design with four replications for each treatment. Each treatment was repeated in four pots randomly arranged inside the growth chamber. Plants were relocated within the chamber twice a week to minimize spatial variations inside the chamber. Treatment effects were determined by the analysis of variance according to the general linear model procedure of SAS (version 8.1; SAS Institute, Cary, NC). Differences among means for treatments were determined by the least significance difference teat (LSD) at the $0.05 P$ level.

\section{Results and Discussion}

Water use of creeping bentgrass as affected by TE application was evaluated as soil water depletion and ET rate. SWC was maintained at $25 \%$ under well-watered conditions throughout the entire study period $(28 \mathrm{~d}$ ) (Fig. 1). The SWC declined to the lowest level of $\approx 5 \%$ by $21 \mathrm{~d}$ of drought and at this level at $28 \mathrm{~d}$ for TE-treated and untreated control plants. However, TEtreated plants had significantly higher water content remained in the soil during the first $14 \mathrm{~d}$ of drought stress than untreated pots, suggesting that TE-treated plants had less rapid depletion of soil water. The less water depletion from the soil seemed not to be related to root growth or root water uptake capacity, as root dry weight did not differ between TE-treated and untreated control, which were $0.4378 \pm 0.0931 \mathrm{~g}$ (mean $\pm \mathrm{SE}, \mathrm{n}=4)$ and $0.4643 \pm 0.0825 \mathrm{~g}$, respectively, after $28 \mathrm{~d}$ of drought. The high soil water content in TE treatment corresponded with the effects of TE on lower ET rate. TE-treated plants under well-watered conditions and during first $14 \mathrm{~d}$ of drought stress had a significantly lower ET rate than untreated control plants (Fig. 2). These results suggest that TE application reduced water use measured as total water loss through ET in creeping bentgrass, which was reflected by the slower water depletion rate from the soil, allowing plants to avoid drought stress. The TE-treated plants had lower and more compact turf canopy (Fig. 3) and significantly lower clipping yield $(0.5036 \pm 0.0221 \mathrm{~g})$ than untreated control $(0.2442 \pm 0.0815 \mathrm{~g})$, which may contribute to lower ET and slower water depletion. The reduction in ET with TE application has been associated with growth inhibition and reduction in leaf area in several turfgrass species, including creeping bentgrass (Ervin and Koski, 2001; Marcum and Jiang, 1997; McCann and Huang, 2007).

The maintenance of favorable water status in leaves is critical for plant survival in dry environments. RWC of

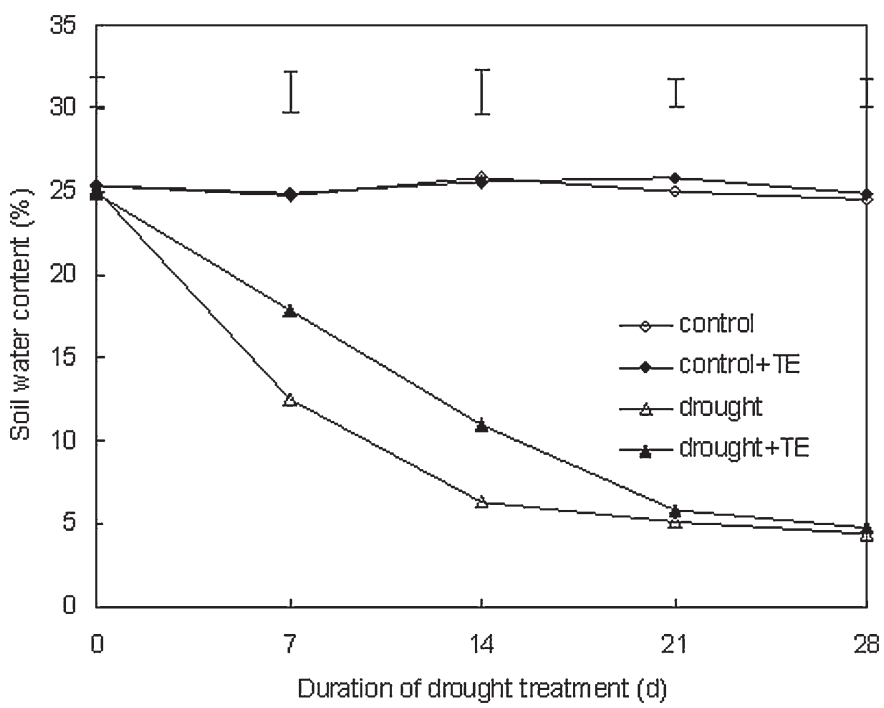

Fig. 1. Soil volumetric water content of creeping bentgrass under well-watered conditions without trinexapac-ethyl (TE) application (control) and with trinexapac-ethyl application (control + TE), drought stress without trinexapacethyl application (drought), and drought stress with trinexapac-ethyl application (drought + TE). Vertical bars indicate LSD values $(P=0.05)$ for treatment comparisons at a given day of drought stress. 


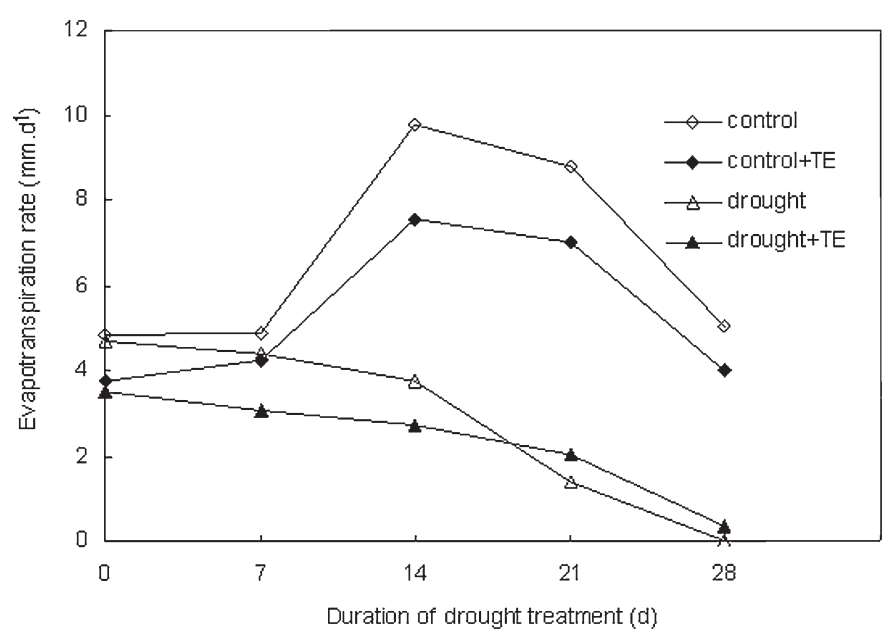

Fig. 2. Evapotranspiration rate of creeping bentgrass under well-watered conditions without trinexapac-ethyl (TE) application (control) and with trinexapac-ethyl application (control + TE), drought stress without trinexapacethyl application (drought), and drought stress with trinexapac-ethyl application (drought + TE). Vertical bars indicate LSD values $(P=0.05)$ for treatment comparisons at a given day of drought stress.

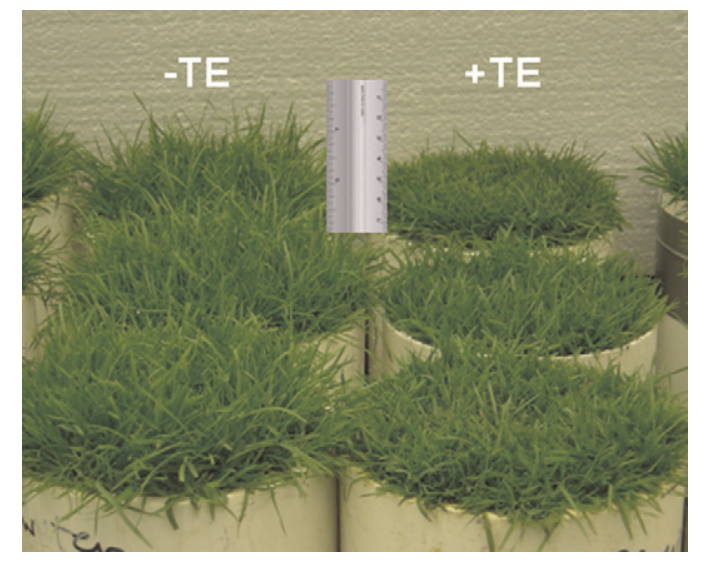

Fig. 3. Shoot growth of creeping bentgrass after $14 \mathrm{~d}$ of trinexapac-ethyl application (+TE) in comparison with untreated control $(-\mathrm{TE})$ at the initiation of drought treatment.

TE-treated and untreated plants under well-watered conditions was maintained at $93 \%$ during the entire treatment period (Fig. 4). RWC declined to $60 \%$ and $40 \%$ for TE-treated and untreated plants, respectively, by the end of drought stress (28 d). TE-treated plants had significantly higher RWC than untreated plants from 14 to $28 \mathrm{~d}$ of drought stress. The maintenance of higher cellular hydration in TE-treated plants could be due to the lower water consumption or less rapid depletion of soil water and/or the higher ability of water retention. High leaf RWC may be the result of water retention through osmotic adjustment (Nilsen and Orcutt, 1996). Our study found that TE-treated plants exhibited lower $\psi_{\mathrm{S}}$ than untreated plants under drought stress (Fig. 5). The lower $\psi_{\mathrm{S}}$ may have contributed to the maintenance of cellular hydration or better drought tolerance in TE-treated plants. The reduction in $\psi_{\mathrm{S}}$ in TE-treated plants could be associated with growth inhibition. Munns (1988) reported that slow growth rate may lead to lower $\psi_{\mathrm{S}}$ due to lower demand on assimilates for growth.

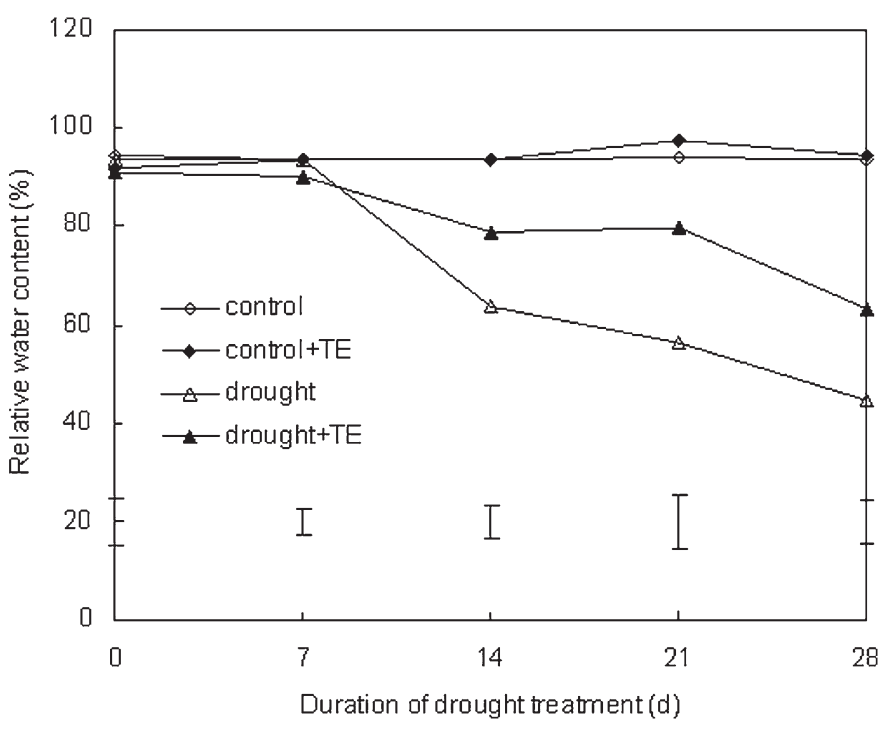

Fig. 4. Leaf relative water content of creeping bentgrass under well-watered conditions without trinexapac-ethyl (TE) application (control) and with trinexapac-ethyl application (control + TE), drought stress without trinexapacethyl application (drought), and drought stress with trinexapac-ethyl application (drought + TE). Vertical bars indicate LSD values $(P=0.05)$ for treatment comparisons at a given day of drought stress.

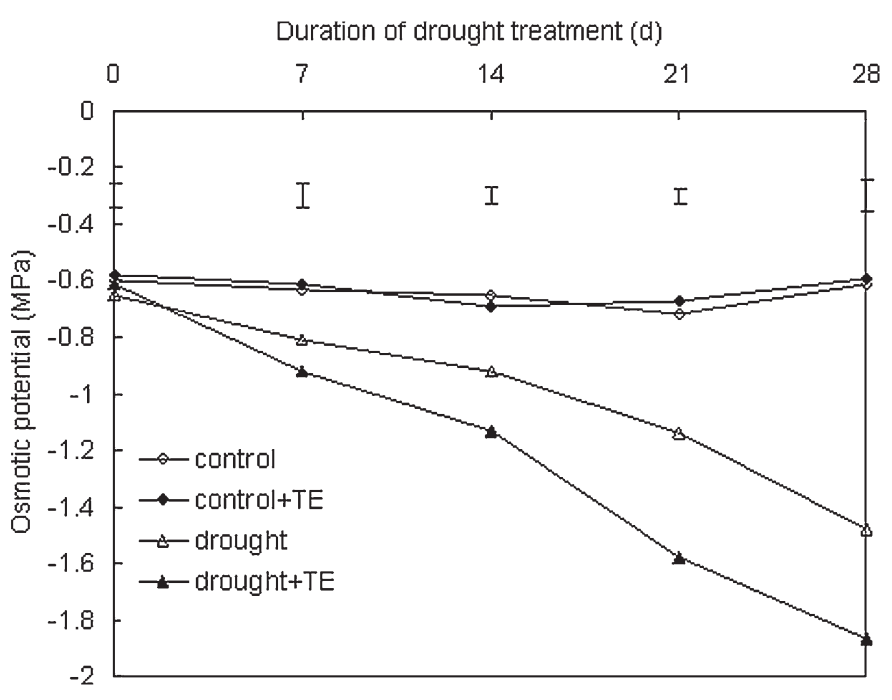

Fig. 5. Leaf $\psi_{\mathrm{S}}$ at full turgor of creeping bentgrass under well-watered conditions without trinexapac-ethyl (TE) application (control) and with trinexapac-ethyl application (control $+\mathrm{TE}$ ), drought stress without trinexapacethyl application (drought), and drought stress with trinexapac-ethyl application (drought $+\mathrm{TE})$. Vertical bars indicate LSD values $(P=0.05)$ for treatment comparisons at a given day of drought stress.

Osmotic adjustment is associated with the accumulation of different solutes (Munns, 1988). In this study, proline content increased under drought stress; however, TE had no significant effects on proline content under well-watered conditions or drought stress (Fig. 6). These results suggest that proline accumulation was induced by drought stress, but was not involved in the osmotic adjustment due to TE application. Soluble sugar content increased with drought stress by $75 \%$ and $100 \%$ in TE-untreated and TE-treated plants, respectively, by $28 \mathrm{~d}$, and was 30\% higher in TE-treated plants than untreated plants at $28 \mathrm{~d}$ of drought stress (Fig. 7). The significant increase 


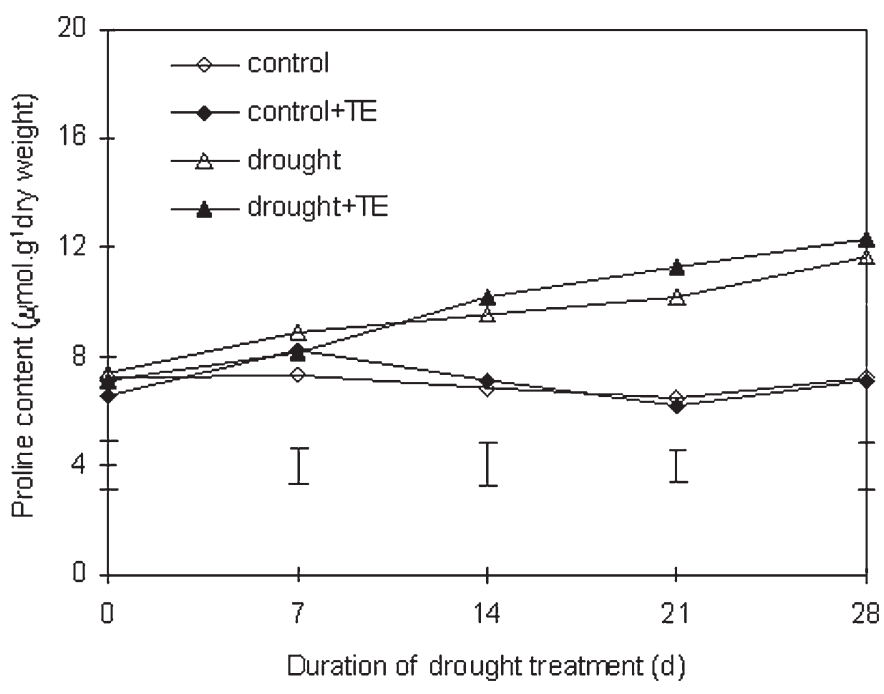

Fig. 6. Proline content in leaves of creeping bentgrass under well-watered conditions without trinexapac-ethyl (TE) application (control) and with trinexapac-ethyl application (control + TE), drought stress without trinexapacethyl application (drought), and drought stress with trinexapac-ethyl application (drought + TE). Vertical bars indicate LSD values $(P=0.05)$ for treatment comparisons at a given day of drought stress.

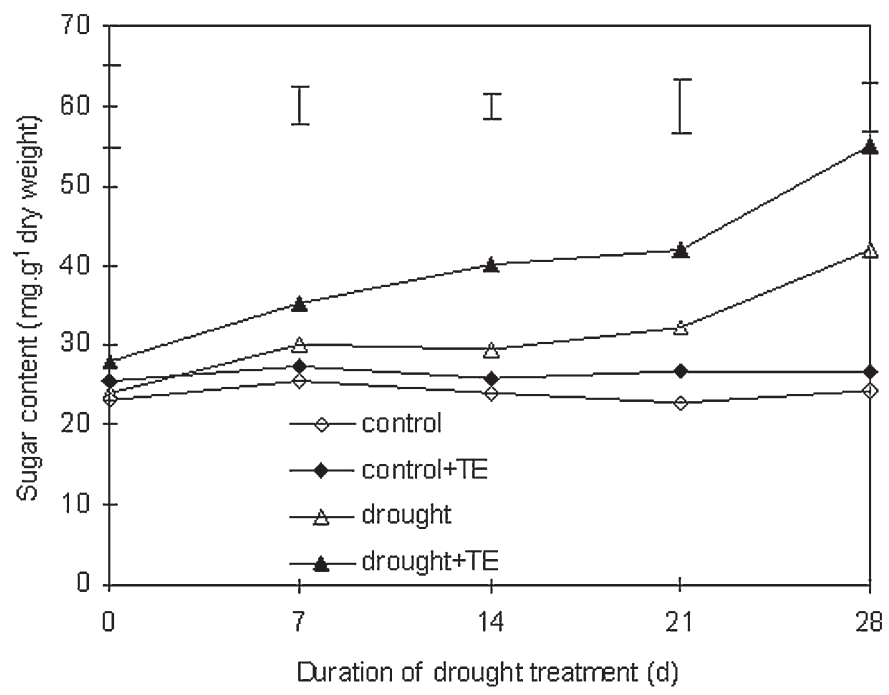

Fig. 7. Water soluble sugar content in leaves of creeping bentgrass under wellwatered conditions without trinexapac-ethyl (TE) application (control) and with trinexapac-ethyl application (control $+\mathrm{TE}$ ), drought stress without trinexapac-ethyl application (drought), and drought stress with trinexapacethyl application (drought + TE). Vertical bars indicate LSD values $(P=0.05)$ for treatment comparisons at a given day of drought stress.

in sugar content in TE-treated plants indicated that TE application resulted in increased sugar accumulation, which may contribute to the lower $\psi_{\mathrm{S}}$. Han et al. (1998) reported that TE affected photoassimilate partitioning to adjacent tillers and increased total nonstructural carbohydrate accumulation under nonwater-limiting conditions. The increase in soluble sugars by TE was most likely due to a reduction in demand for sugar for growth, instead of a direct mechanism of TE on osmotic adjustment intended for drought tolerance. In addition, the reduction of growth and increase available water in the cells could have contributed to a reduction of drought damage, thereby allowing TE-treated plants to be more able to mobilize carbohydrates into free sugars for osmotic adjustment. However, the specific mechanisms regarding how TE affects soluble sugar accumulation under drought stress are not well understood.

Two major inorganic solutes, $\mathrm{K}$ and $\mathrm{Ca}$, associated with osmotic regulation responded differently to drought stress and TE application. Leaf $\mathrm{K}$ content was unaffected by drought stress, but increased by $18 \%$ with TE treatment under drought stress (Table 1). Leaf Ca content decreased under drought stress for TE-treated or untreated plants. However, TE-treated plants had significantly higher $\mathrm{Ca}$ content than untreated plants under well-watered conditions (18\% higher) and drought stress $(22 \%$ higher). It appeared that sugar accumulation may be a more important contributor to the reduction in $\psi_{\mathrm{S}}$ compared with proline and the two inorganic solutes ( $\mathrm{K}$ and $\mathrm{Ca}$ ) in TE-treated creeping bentgrass.

TE-treated plants exhibited significantly higher turf quality from 14 to $28 \mathrm{~d}$ of drought stress (Fig. 8A). TE-treated plants also maintained significantly higher leaf photochemical efficiency (Fv/Fm) after $21 \mathrm{~d}$ of drought stress (Fig. 8B). Similar results of positive effects of TE on turf quality and $\mathrm{Fv} / \mathrm{Fm}$ have been reported for creeping bentgrass exposed to combined drought and heat stress (McCann and Huang, 2007). Zhang and Schmidt (2000) also reported enhanced photochemical activities by $\mathrm{TE}$ in creeping bentgrass. Under nonwater-limiting conditions, increases in turf quality with TE application have been associated with increases in tiller density and chlorophyll content (Fagerness and Yelverton, 2001; McCullough et al., 2006; Stier and Rogers, 2001). However, the mechanisms associated with improved photochemical efficiency caused by TE under drought stress are not well understood, Nevertheless, our study suggests that the reduction in water depletion and ET rate, and maintenance of higher RWC and osmotic adjustment associated with TE application may enhance plant survival in a prolonged period of drought stress, as demonstrated by the ability of the plants to maintain better turf quality and photosynthetic efficiency.

In summary, our results suggest that the positive effects of $\mathrm{TE}$ on creeping bentgrass survival in a prolonged period of drought stress were associated with the reduction in water use and increases in osmotic adjustment through solute accumulation, particularly soluble sugars, under the controlled environment conditions. Similar physiological mechanisms of TE effects on drought performance of turfgrass may be applicable under field conditions, but it should be noted that the effectiveness of TE may vary from a controlled environment to field conditions with varying influences of temperatures and light intensities.

Table 1. Inorganic solute concentration in leaves of creeping bentgrass under well-watered and drought conditions as affected with trinexapac-ethyl $(+\mathrm{TE})$ or without trinexapac-ethyl treatment (-TE).

\begin{tabular}{lccc}
\hline Treatment & TE treatment & $\mathrm{Ca}\left(\mathrm{mmol} \cdot \mathrm{L}^{-1}\right)$ & $\mathrm{K}\left(\mathrm{mmol} \cdot \mathrm{L}^{-1}\right)$ \\
\hline Well-watered & $-\mathrm{TE}$ & $6.8 \mathrm{~b}$ & $105.2 \mathrm{~b}$ \\
& $+\mathrm{TE}$ & $8.0 \mathrm{a}$ & $110.0 \mathrm{~b}$ \\
Drought & $-\mathrm{TE}$ & $5.7 \mathrm{c}$ & $115.2 \mathrm{~b}$ \\
& $+\mathrm{TE}$ & $6.9 \mathrm{~b}$ & $135.6 \mathrm{a}$
\end{tabular}

*Means followed by the same letter within a column indicate no significant differences between treatments base on LSD test at $P=0.05$. 

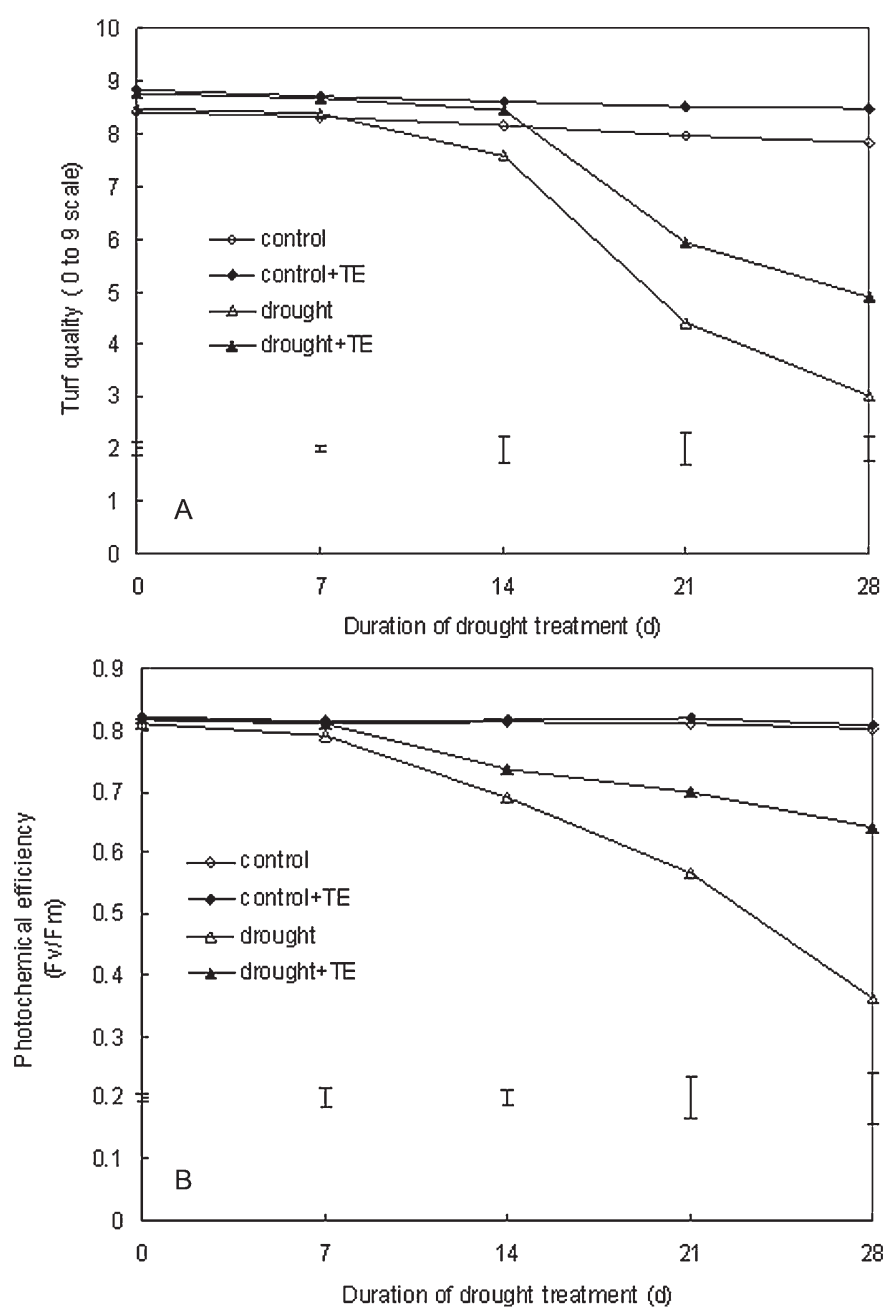

Fig. 8. Turf quality (A; visually rated on the scale of $0-9$, with 9 being the best) and leaf photochemical efficiency $(\mathrm{Fv} / \mathrm{Fm}$; B) of creeping bentgrass under well-watered conditions without trinexapac-ethyl (TE) application (control) and with trinexapac-ethyl application (control $+\mathrm{TE}$ ), drought stress without trinexapac-ethyl application (drought), and drought stress with trinexapacethyl application (drought $+\mathrm{TE})$. Vertical bars indicate LSD values $(P=0.05)$ for treatment comparisons at a given day of drought stress.

\section{Literature Cited}

Baldwin, C., H. Liu, L.B. McCarty, W.L. Bauerle, and J.E. Toler. 2006. Effects of trinexapac-ethyl on the salinity tolerance of two ultradwarf bermudagrass cultivars. HortScience 41:808-814.

Barrs, H.D. and P.E. Weatherley. 1962. A re-examination of the relative turgidity techniques for estimating water deficits in leaves. Aust. J. Biol. Sci. 15:413-428.

Bates, L.S., R.P. Waldren, and I.D. Teare. 1973. Rapid determination of free proline for water-stress studies. Plant Soil 39:205-207.

Beard, J.B. 1973. Turfgrass: Science and culture. Prentice-Hall, Englewood Cliffs, NJ.

Blum, A. 1988. Plant breeding for stress environments. CRC Press, Boca Raton, FL.
Buysse, J. and R. Merckx. 1993. An improved colorimetric method to quantify sugar content of plant tissue. J. Expt. Bot. 44:16271629.

Chaves, M.M., J.P. Maroco, and J.S. Pereira. 2003. Understanding plant responses to drought-from genes to the whole plant. Funct. Plant Biol. 30:239-264.

Ervin, E.H. and A.J. Koski. 2001. Trinexapac-ethyl increases kentucky bluegrass leaf cell density and chlorophyll concentration. HortScience 36:787-789.

Fagerness, M.J. and F.H. Yelverton. 2001. Plant growth regulator and mowing height effects on seasonal root growth of Penncross creeping bentgrass. Crop Sci. 41:1901-1905.

Fagerness, M.J., F.H. Yelverton, D.P. Livingston, and T.W. Rufty. 2002. Temperature and trinexapac-ethyl effects on bermudagrass growth, dormancy, and freezing tolerance. Crop Sci. 42:853-858.

Han, S.W., T.W. Fermanian, J.A. Juvik, and L.A. Spomer. 1998. Growth retardant effects on visual quality and nonstructural carbohydrates of creeping bentgrass. HortScience 33:1197-1199.

Heckman, N.L., G.L. Horst, R.E. Gaussoin, and L.J. Young. 2001. Heat tolerance of kentucky bluegrass as affected by trinexapac-ethyl. HortScience 36:365-367.

Jiang, H. and J. Fry. 1998. Drought responses of perennial ryegrass treated with plant growth regulators. HortScience 33:270-273.

Jiang, Y. and B. Huang. 2001. Osmotic adjustment associated with drought-preconditioning enhanced heat tolerance in kentucky bluegrass. Crop Sci. 41:1168-1173.

Lickfeldt, D.W., D.S. Gardner, B.E. Branham, and T.B. Voigt. 2001. Implications of repeated trinexapac-ethyl applications on kentucky bluegrass. Agron. J. 93:1164-1168.

Marcum, K.B. and H. Jiang. 1997. Effects of plant growth regulators on tall fescue rooting and water use. J. Turfgrass Mgt. 2:13-27.

McCann, S.E. and B. Huang. 2007. Effects of trinexapac-ethyl foliar application on creeping bentgrass responses to combined drought and heat stress. Crop Sci. 47:2121-2128.

McCullough, P., H. Liu, L. McCarty, T. Whitwell, and J.E. Toler. 2006. Bermudagrass putting green growth, color and nutrient partitioning influenced by nitrogen and trinexapac-ethyl. Crop Sci. 46:1515-1525.

Munns, R. 1988. Why measure osmotic adjustment? Aust. J. Plant Physiol. 15:717-726.

Nilsen, E.T. and D.M. Orcutt. 1996. Physiology of plants under stress: Abiotic factors. Wiley, New York.

Rachmilevitch, S., M. DaCosta, and B. Huang. 2006. Physiological and biochemical indicators for stress tolerance, p. 321-356. In: B. Huang (ed.). Plant-environment interactions. 3rd ed. CRC Press, Boca Raton, FL.

Stier, J.C. and J.N. Rogers. 2001. Trinexapac-ethyl and iron effects on supina and kentucky bluegrasses under low irradiance. Crop Sci. 41:457-465.

Topp, G.C., J.L. Davis, and A.P. Annan. 1980. Electromagnetic determination of soil water content: Measurement in coaxial transmission lines. Water Resource Res. 16:574-582.

Young, M.H., P.J. Wierenga, and C.F. Mancino. 1997. Monitoring near-surface soil water storage in turfgrass using time domain reflectometry and weighing lysimetry. Soil Sci. Soc. Amer. J. 61: $1138-1146$.

Zhang, X. and R.E. Schmidt. 2000. Application of trinexapac-ethyl and propiconazole enhances superoxide dismutase and photochemical activity in creeping bentgrass. J. Amer. Soc. Hort. Sci. 125:4751. 